\title{
04.1
}

\section{Экспериментальное и теоретическое исследование схождения тороидальной ударной волны}

\author{
(ㄱ А.С. Барышников, И.В. Басаргин, Н.О. Безверхний, Н.А. Монахов, П.А. Попов \\ Физико-технический институт им. А.Ф. Иофрфе РАН, Санкт-Петербург, Россия \\ E-mail: al.bar@mail.ioffe.ru
}

Поступило в Редакцию 1 июня 2020 г.

В окончательной редакции 28 апреля 2021 г.

Принято к публикации 4 мая 2021 г.

\begin{abstract}
Экспериментально и теоретически исследуется схождение тороидальной ударной волны, образующейся в кольцевом электрическом разряднике. Для расчетов схождения внутренней волны использовано уравнение „геометрической динамики“ Честера-Чизнелла-Уизема, полученное для распространения ударной волны с учетом физико-химических превращений в газе. Проведено сравнение экспериментальных и расчетных результатов. Отмечено увеличение инкремента нарастания возмущений на фронте для химически реагирующих газов.
\end{abstract}

Ключевые слова: сходящаяся ударная волна, кольцевой электрический разрядник, химические процессы, метод Честера-Чизнелла-Уизема.

DOI: 10.21883/PJTF.2021.15.51231.18405

Для равномерного сжатия мишени при инерционном способе термоядерного синтеза $[1,2]$ необходима сглаженная начальная форма сходящейся волны. В тороидальном взрыве имеется две стадии схождения. Сначала (на первой стадии) отрицательная главная кривизна внутренней поверхности волны значительно больше положительной, внутренняя волна замедляется, и локальные возмущения на ней сглаживаются [3]. На второй стадии с уширением тора соотношение между отрицательной и положительной кривизной внутренней поверхности волны меняется на обратное, и ударная волна внутри тора ведет себя уже как цилиндрическая сходящаяся ударная волна, которая, как известно [4], неустойчива. Поскольку физико-химические процессы (ионизация, диссоциация, рекомбинация) для термоядерного синтеза, естественно, имеют место, необходимо выяснить их влияние на эволюцию начальных возмущений сходящейся волны. Особенно это важно, если возмущения возникают на фронте при генерации волны дискретным рядом источников, а не равномерным взрывом проволочных колец [3].

На рис. 1 показана схема электрического разрядника, генерирующего в эксперименте тороидальную ударную волну, который представляет собой кольцо сплошной заземленной пластины, над которым параллельно плоскости кольца расположены 24 латунных дисковых анода на расстоянии $2 \mathrm{~mm}$ от кольца, так что разрядные промежутки перпендикулярны плоскости кольца. На рис. 2 представлены фотографии схождения ударной волны при разряде емкости $C=0.5 \mu \mathrm{F}$, заряженной до напряжения $U=30 \mathrm{kV}$. Видны обе стадии схождения ударной тороидальной волны (рис. 2, $a$ и $b$ ). Для этих серий экспериментов характерно образование нескольких ударных волн, сходных по форме с первой, но более сла- бых по интенсивности. Анализ полученных фотографий показывает, что первичная ударная волна создается в результате взаимодействия ударных волн, генерируемых соседними разрядными промежутками. Вторичные же волны образуются в результате взаимодействия ударных волн, генерируемых разрядными промежутками, расположенными друг от друга через несколько промежутков.

Методическая отработка кольцевого разрядника сводилась к апробированию различных схем расположения электродов, изменению межэлектродного зазора, формы и материала электродов, а также емкости и напряжения зарядки конденсаторов. На рис. 3 изображена зависимость числа Маха $\mathrm{M}$ сходящейся тороидальной волны от ее радиуса $R$.

Сплошные линии на рис. 3 - результаты расчетов. Для расчета симметричной цилиндрической сходящейся ударной волны существуют надежные методы [5-7]. Вместе с тем в экспериментах проявляется неустойчивость сходящейся ударной волны [4], которая нарушает симметрию (рис. 2, $b$ ). В особенности это касается ударных волн для умеренных чисел Маха, на которые влияют также физико-химические свойства среды. В то же время известно, что даже малые отклонения от цилиндрической формы сходящейся волны отражаются на ее кумуляции. Следовательно, для решения задач, связанных с взрывами сложной формы, к которым относится и тороидальный взрыв, целесообразно разрабатывать метод расчета волны любой произвольной конфигурации, а не только цилиндрической. Прямое численное моделирование турбулизованного потока за неустойчивой волной требует больших вычислительных мощностей [8]. Поэтому обычно используют упрощенные, но достаточно точные методы, к которым относится метод Честера-Чизнелла-Уизема [4]. Числен- 


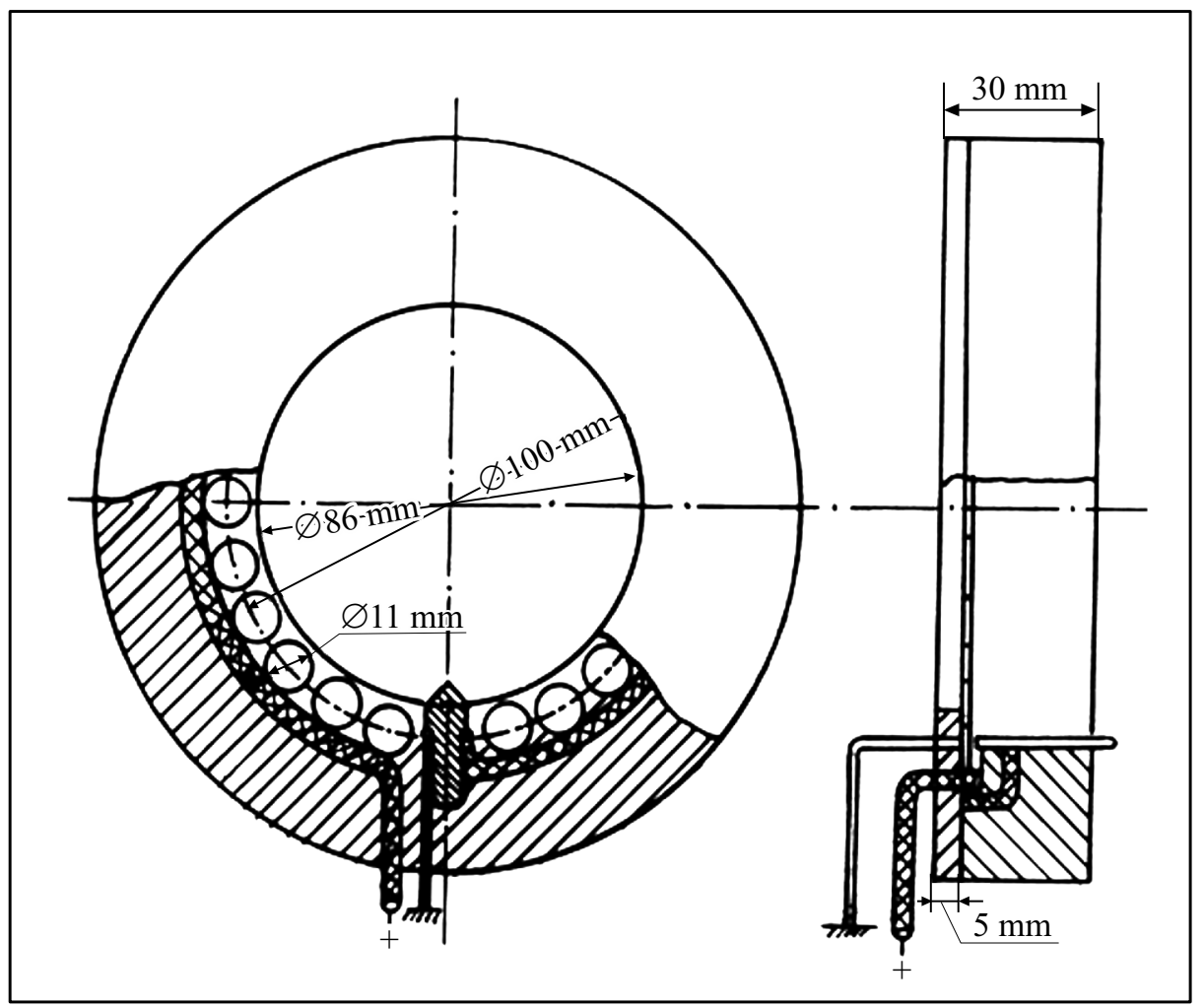

Рис. 1. Конструкция кольцевого электроразрядника. Ряд окружностей по периметру - латунные дисковые электроды (аноды), расположенные над сплошной заземленной пластиной в форме кольца на расстоянии $2 \mathrm{~mm}$.

ный метод, основанный на этом методе, был разработан в [9]. В нем весь фронт ударной волны разбивается на малые элементы, перемещение которых за малый промежуток времени описывается уравнением Честера-Чизнелла-Уизема [4]. В настоящей работе уравнение получено и для реагирующих сред с учетом энергии, идущей на физико-химические превращения на фронте ударной волны $-Q$ (параметр $D=Q / I_{1}$, где $I_{1}$ - энтальпия газа перед волной):

$$
\frac{\mathrm{M}}{\mathrm{M}^{2}-1} \lambda_{D}(\mathrm{M}) \frac{d \mathrm{M}}{d x}+\frac{1}{A} \frac{d A}{d x}=0
$$

Здесь

$$
\begin{aligned}
\lambda_{D}(\mathrm{M})= & \left(\mathrm{M}^{2}-1\right)\left(1+\frac{1}{\mu_{D}}\right)\left\{\left[\frac{P_{1} \sigma}{P}+\frac{a_{1}}{a}\left(\frac{\sigma}{\mathrm{M}}-\frac{\Delta}{\mathrm{M}^{2}}\right)\right]\right. \\
- & \left.\psi\left(\frac{P_{1}}{P} \mathrm{M}+\frac{a_{1}}{a}\right) \frac{d D}{d \mathrm{M}}\right\}, \\
& \mu_{D}=\frac{a_{1}}{a} \frac{\Delta}{\mathrm{M}(\gamma+1)}, \quad \frac{a_{1}}{a}=\sqrt{\frac{P_{1} / P}{\rho / \rho_{1}}}, \\
\sigma= & 2 \mathrm{M}+\frac{2\left(\mathrm{M}^{2}-1\right) \mathrm{M}-2(\gamma+1) \mathrm{M} D(\mathrm{M})}{\left[\left(\mathrm{M}^{2}-1\right)^{2}-2[\gamma+1] \mathrm{M}^{2} D(\mathrm{M})\right]^{1 / 2}}, \\
\Delta= & \mathrm{M}^{2}-1+\left[\left(\mathrm{M}^{2}-1\right)^{2}-2(\gamma+1) \mathrm{M}^{2} D\right]^{1 / 2}
\end{aligned}
$$

$$
\psi=\frac{(\gamma+1) \mathrm{M}}{\left[\left(\mathrm{M}^{2}-1\right)^{2}-2[\gamma+1] \mathrm{M}^{2} D(\mathrm{M})\right]^{1 / 2}},
$$

M - число Маха элемента ударной волны, $A$ площадь элемента, отнесенная к значению в начальный момент времени, $a, P, \rho-$ скорость звука, давление и плотность за ударной волной, $a_{1}, P_{1}, \rho_{1}$ - то же перед волной. Видно, что $\lambda_{D}(\mathrm{M})$ зависит не только от самой функции $D(\mathrm{M})$, но и от ее производной $d D / d \mathrm{M}$.

Анализ уравнения (1) показывает, что при достаточно больших М и конечных $D$ процесс схождения не зависит от сорта среды, что согласуется с принципом гиперзвуковой стабилизации. Почти для всех М отличия от значений в идеальном газе $(D=0)$ нет, кроме окрестности некоторых „критических“ точек $\mathrm{M}_{c r}$. Эти точки, в которых $\lambda_{D}(\mathrm{M})$ стремится к бесконечности, являются границами области существования функции $\lambda_{D}(\mathrm{M})$. Применение обычных методов расчета с постоянным шагом интегрирования не позволяет точно рассчитывать „жесткие“ системы уравнений, к которым относится и (1), поэтому для численного интегрирования применялся метод Гира [10]. Точность расчета сходящейся волны определялась сравнением с теорией Гудерлея [4]. Она оказалась не хуже точности расчетов [9] (2-3\%), а для более сильных ударных волн менее $1 \%$.

На рис. 3 приведены некоторые результаты расчетов в воздухе для цилиндрической сходящейся ударной 

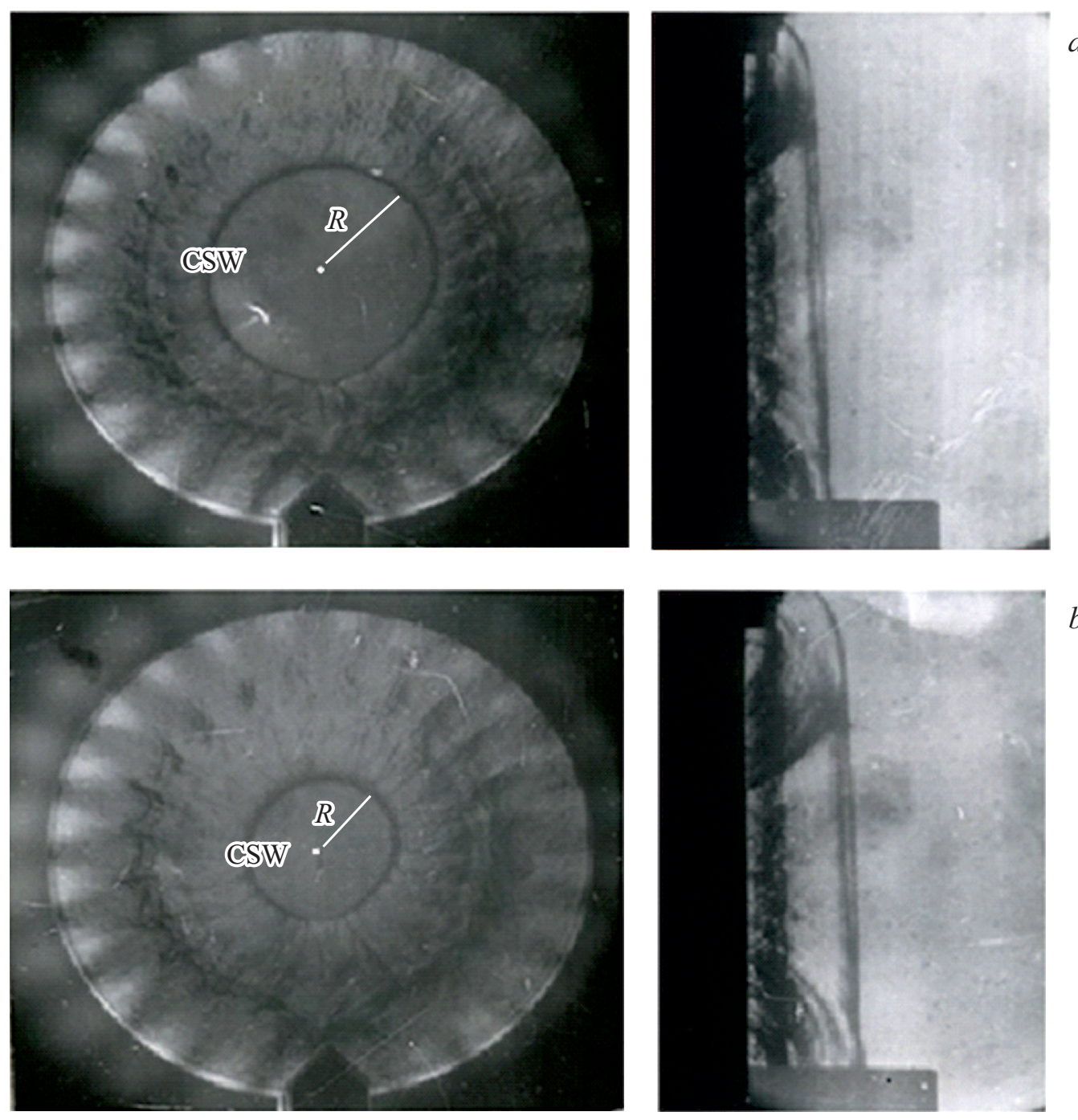

Рис. 2. Экспериментальные результаты по схождению тороидального разряда в воздухе. $a-30 \mu \mathrm{s}, b-40 \mu \mathrm{s}$. Слева - вид сверху на тор, справа - вид сбоку. $R$ - радиус сходящейся волны, CSW - фронт сходящейся волны. Электроды расположены по периметру кольца.

Расчет эволюции синусоидальных возмущений в $\mathrm{CF}_{2} \mathrm{Cl}_{2}$ и в идеальном газе $(D=0)$ при $\gamma=1.14$

\begin{tabular}{c|c|c|c|c|c|c|c}
\hline Время, s & Параметр $D$ & $\max R, \mathrm{~mm}$ & $\min R, \mathrm{~mm}$ & $\begin{array}{c}\text { Радиус } \\
\text { волны, } \mathrm{mm}\end{array}$ & Амплитуда, $\mathrm{mm}$ & $\begin{array}{c}\text { Относительная } \\
\text { амплитуда }\end{array}$ & Инкремент \\
\hline $\begin{array}{c}0 \\
\text { (начальная }\end{array}$ & & 52.0 & 48.0 & 50.0 & 2.0 & 0.04 & \\
волна) & & & & & & \\
$0.89 \cdot 10^{-5}$ & 0.00 & 45.9 & 42.1 & 44.0 & 1.9 & 0.04318 & 0.0765 \\
& 0.58 & 46.0 & 42.0 & 44.0 & 2.0 & 0.04545 & 0.1278
\end{tabular}

волны. Начальный радиус волны $R_{0}=50 \mathrm{~mm}$, давление и температура перед волной $P_{1}=10^{5} \mathrm{~Pa}, T_{1}=300 \mathrm{~K}$, начальные числа Маха $\mathrm{M}_{0}=3,2,1.5,1.2$. Расчетные кривые хорошо согласуются с экспериментальными. На завершающих этапах кумуляции имеется расхождение результатов, что связано с более высокой погрешностью измерения скорости вблизи точки кумуляции.
В таблице представлен пример расчетов эволюции синусоидальных возмущений фронта сходящейся ударной волны малой, но конечной амплитуды $\Delta r=2 \mathrm{~mm}$ (при начальном радиусе волны $R_{0}=50 \mathrm{~mm}$ ) в химически реагирующем $\mathrm{CF}_{2} \mathrm{Cl}_{2}$ в сравнении с расчетами в идеальном газе с тем же показателем адиабаты $\gamma=1.14$ и с тем же начальным числом Маха волны $\mathrm{M}_{0}=2.09$. Именно 


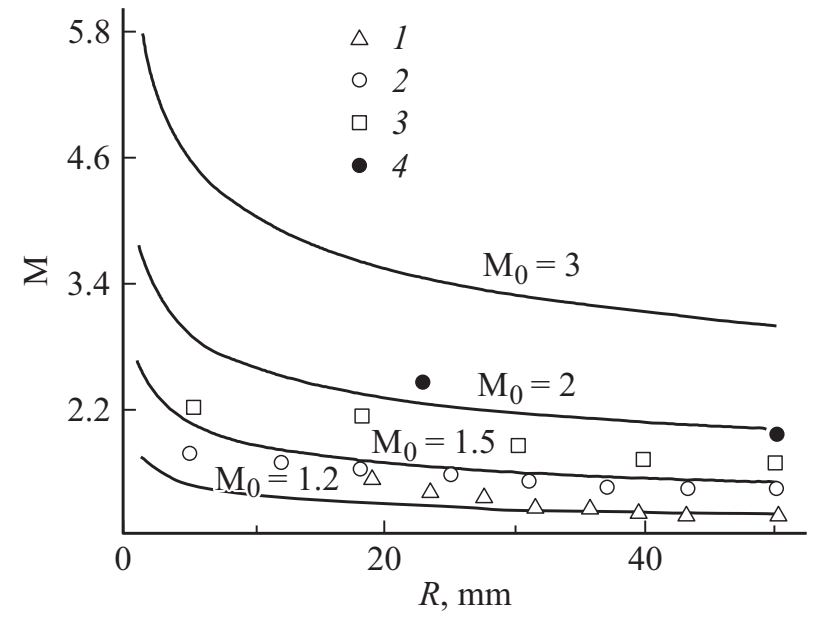

Pис. 3. Рассчитанные в воздухе (сплошные линии) $\left(\mathrm{M}_{0}\right.$ над кривыми - начальные значения чисел Маха ударной волны в расчетах) и экспериментальные (точки) зависимости М от радиуса сходящейся волны $R$, представленной на рис. 2 . $\mathrm{M}_{0}=1.18$ (1), 1.41 (2), 1.67 (3) и 1.9 (4).

в этом газе и при этих режимах наблюдается влияние физико-химических реакций на устойчивость головной ударной волны [11].

Начальное число Маха было выбрано вблизи одной из „критических“ точек, о которых шла речь выше: $\mathrm{M}_{c r}=2.08$. Инкремент нарастания возмущений $\delta=\ln \left((\Delta r / R)_{0} /(\Delta r / R)_{t}\right)$ в химически реагирующем газе оказался на $70 \%$ больше, чем в идеальном.

Таким образом, при некоторых числах Маха возмущения на волне могут расти почти в 2 раза быстрее, чем это следует из теории схождения в идеальном газе. Это может сказаться на форме сходящейся волны и на конечной кумуляции.

\section{Благодарности}

Авторы выражают благодарность С.В. Бобашеву за полезные обсуждения результатов.

\section{Финансирование работы}

Финансирование

осуществлялось

ФТИ им. А.Ф. Иоффе РАН.

\section{Конфликт интересов}

Авторы заявляют, что у них нет конфликта интересов.
[4] Дж. Уизем, Линейные и нелинейные волны (Мир, М., 1977).

[5] А.А. Чархачьян, К.В. Хищенко, В.В. Милявский, В.Е. Фортов, А.А. Фролова, И.В. Ломоносов, Л.В. Шуршалов, ЖТФ, 75 (8), 15 (2005).

[6] А.Д. Зубов, М.А. Зубов, Вестн. Челяб. гос. ун-та, № 14 (268), Физика (вып. 13), 32 (2012).

[7] Э.М. Бархударов, И.А. Коссый, М.О. Мдивнишвили, И.В. Соколов, М.И. Тактакишвили, Изв. АН СССР. Механика жидкости и газа, № 2, 164 (1988).

[8] У. Шумани, Г. Гретцбах, Л. Кляйзер, в сб.: Методы расчета турбулентных течений, под ред. В. Колльмана (Мир, М., 1984), с. 103.

[9] K. Fong, B. Ahlborn, Phys. Fluids, 22, 416 (1979).

[10] C.W. Gear, Commun. ACM, 14, 176 (1971).

[11] А.С. Барышников, И.В. Басаргин, С.В. Бобашев, Н.А. Монахов, П.А. Попов, В.А. Сахаров, М.В. Чистякова, Инж.физ. журн., 89 (5), 1232 (2016).

\section{Список литературы}

[1] R. Betti, O.A. Hurricane, Nature Phys., 12, 435 (2016).

[2] И.В. Соколов, УФН, 160 (11), 143 (1990).

[3] У. Юсупалиев, в сб.: Ломоносовские чтения-2010 (Секция физики). Тез. докл. (МГУ, М., 2010), с. 39. 